\title{
Predição da composição corporal e da carcaça a partir da seção entre a 9a e 11a costelas em bovinos Nelore ${ }^{1}$
}

\section{Marcos Inácio Marcondes ${ }^{2}$, Sebastião de Campos Valadares Filho ${ }^{3}$, Pedro Veiga Rodrigues Paulino $^{3}$, Edenio Detmann ${ }^{3}$, Rilene Ferreira Diniz Valadares ${ }^{3}$, Tathyane Ramalho Santos ${ }^{3}$, Luciana Lacerda Diniz ${ }^{3}$}

\footnotetext{
${ }^{1}$ Projeto financiado pela Fundação de Amparo à Pesquisa de Minas Gerais (FAPEMIG)/Centro Nacional de Pesquisa (CNPq)/Pronex. 2 Doutorando, DZO-UFV.

${ }^{3}$ Universidade Federal de Viçosa, Viçosa-MG, CEP: 36570-000.
}

RESUMO - Objetivou-se avaliar as equações de Hankins \& Howe para estimação da composição física da carcaça e as de Paulino para estimação da composição de macrominerais no corpo vazio de bovinos Nelore. Foram utilizados nove machos castrados, nove machos não-castrados e nove fêmeas. Três animais de cada classe foram abatidos ao início do experimento como referência. Os 18 animais remanescentes foram alimentados durante 112 dias com uma ração com 12,5\% de proteína bruta, e concentrado, fornecido na proporção de 1,00 ou 1,25\% do PV, e abatidos ao final para determinação da composição corporal. As composições física e química foram determinadas em uma amostra entre a 9a e 11aㅡ costelas (seção HH) da meiacarcaça esquerda e na meia-carcaça direita inteira, a qual foi totalmente dissecada. A seção HH não possibilitou estimar corretamente a composição física de nenhum dos componentes da carcaça, e apenas a equação proposta para cálcio foi eficiente para estimar a porcentagem de cálcio no corpo vazio. Propõe-se o uso de novas equações para estimar o conteúdo corporal dos macrominerais a partir de sua concentração na seção HH. As equações de Hankins \& Howe não estimam corretamente a composição física da carcaça de bovinos Nelore, no entanto, é possível estimar a composição de macrominerais no corpo vazio de Nelore a partir da seção HH.

Palavras-chave: bovinos de corte, composição física, composição química, corte das costelas, minerais, seção HH

\section{Predicting body and carcass composition using the section between $9^{\text {th }}$ and $11^{\text {th }}$ ribs in Nellore cattle}

\begin{abstract}
The objective of this study was to evaluate the Hankins and Howe equations, to estimate the carcass physical composition, and the Paulino equations, to estimate the empty body weight macromineral composition of Nellore cattle. Twenty seven Nellore animls (9 bulls, 9 steers and 9 heifers) were used, and nine animals (three of each gender) were slaughtered at the beginning and formed the reference group. The 18 remaining animals (6 of each gender) were allotted in two levels of concentrate offer (1.0\% and 1.25\% live weight) and were fed over 112 days. At the end of the trial all the animals were slaughtered to determine the empty body weight and physical and chemical body composition using the right carcass half. From left carcass half one sample from $9^{\text {th }}$ to $11^{\text {th }}$ ribs (HH section) was obtained. The HH section did not estimate well the physical carcass composition. The Paulino equation was efficient in estimating the Ca concentration in the empty body weight. New equations were proposed for all the macrominerals to estimate their contents in empty body weight using the HH section. It was concluded that the Hankins and Howe equations did not correctly estimate the carcass physical composition in Nellore cattle, and that the macromineral composition can be estimated using the HH section in Nellore cattle.
\end{abstract}

Key Words: beef cattle, chemical composition, HH section, macromineral, physic composition

\section{Introdução}

A raça Nelore é atualmente a mais difundida no Brasil e tem grande importância no crescimento da pecuária de corte nacional. Entretanto, os profissionais da área ainda utilizam tabelas internacionais para formular rações e suple- mentos para esses animais. Segundo o NRC (1996), animais zebuínos apresentam exigência de mantença $10 \%$ menor que as de animais taurinos. Portanto, determinar as exigências nutricionais desses animais significa gerar tecnologia de produção adequada às condições brasileiras, notadamente distintas daquelas presentes em países de clima temperado. 
A composição corporal deve ser obtida por meio da dissecação total de uma das meia-carcaças do animal, o que torna o processo laborioso, além de impedir a comercialização da meia-carcaça, fazendo com que seja um processo de alto custo experimental. O método do corte das costelas (Hankins \& Howe, 1946) têm sido alvo de validação para as condições brasileiras, onde predominam animais zebuínos. Como esse método foi desenvolvido com taurinos, que apresentam padrão de deposição dos constituintes corporais, principalmente de gordura, distinto daquele observado em animais zebuínos, sua aplicabilidade no Brasil passou a ser questionada. Lanna (1988), Silva

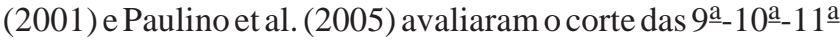
costelas como um estimador da composição da carcaça e do corpo vazio e concluíram que as equações desenvolvidas por Hankins \& Howe (1946) não foram totalmente aplicáveis a animais zebuínos. Portanto, a utilização da seção entre a 9 a e 11 a costelas para estimar a composição corporal de zebuínos ainda carece de mais estudos e validações. Entretanto, apenas Paulino (2002) fez estudos utilizando a seção HH para estimar a composição corporal de macrominerais no peso de corpo vazio de bovinos zebuínos, assim, é necessária a verificação dessas equações para que haja utilização segura em maior escala.

Dessa forma, objetivou-se com este trabalho avaliar as equações de Hankins \& Howe (1946), para estimação da composição física da carcaça, e as de Paulino (2002), para estimação da composição de macrominerais no corpo vazio de bovinos Nelore.

\section{Materiais e Métodos}

Foram utilizados 27 bovinos Nelore: nove machos castrados, nove machos inteiros e nove fêmeas, com pesos vivo iniciais de 285, $25 \pm 3,69 ; 293,00 \pm 7,22$ e 264,00 $\pm 4,00 \mathrm{~kg}$, respectivamente. Os animais foram confinados em baias individuais com comedourose bebedouros e área total de $30 \mathrm{~m}^{2}$ ( $8 \mathrm{~m}^{2}$ cobertos com telhas de amianto e recobertos por piso de concreto).

Inicialmente, todos os animais foram pesados, identificados, vermifugados e mantidos por 30 dias em período de adaptação recebendo a mesma dieta, constituída de 75\% de silagem de milho, 25\% de concentrado e $12,5 \%$ de PB na MS da dieta.

Após esse período, três animais de cada classe sexual foram abatidos e serviram de referência para estimação da composição corporal inicial dos animais remanescentes. Os 18 animais restantes, seis de cada classes sexual, foram divididos em dois níveis de oferta de concentrado: 1,00\% (dieta 1) e $1,25 \%$ do peso vivo (dieta 2 ). Utilizou-se delineamento inteiramente casualizado, em esquema fatorial $2 \times 3$, composto de dois níveis de oferta de concentrado e três classes sexuais, com três repetições.

Os animais foram alimentados duas vezes ao dia, às $7 \mathrm{~h}$ e $16 \mathrm{~h}$ e as rações formuladas para serem isoprotéicas (12,5\% PB na matéria seca total). Como volumoso foi utilizada silagem de milho, fornecida à vontade. O concentrado foi formulado à base de milho moído, farelo de soja, sal mineral, sal comum, calcário, ureia e sulfato de amônio (9:1). As sobras foram ajustadas para ficar entre 5 e $10 \%$ da matéria seca total fornecida, com água permanentemente à disposição dos animais.

A relação volumoso:concentrado oferecida foi, em média, 68:32 e 62:38 para as dietas 1 e 2, respectivamente, com base na matéria seca (Tabelas 1, 2 e 3).

Tabela 1 - Proporção dos ingredientes nos concentrados e nas dietas experimentais, com base na matéria seca

\begin{tabular}{|c|c|c|c|c|}
\hline \multirow[t]{2}{*}{ Ingrediente } & \multicolumn{2}{|c|}{$1,00 \%$ do PV } & \multicolumn{2}{|c|}{$1,25 \%$ do PV } \\
\hline & Concentrado & Dieta & Concentrado & Dieta \\
\hline Silagem de milho, \% & - & 68,11 & - & 61,67 \\
\hline Farelo de soja, \% & 18,98 & 6,05 & 10,88 & 4,17 \\
\hline Milho moído, \% & 74,18 & 23,66 & 83,41 & 31,97 \\
\hline Calcário, \% & 0,96 & 0,31 & 1,08 & 0,42 \\
\hline Mistura mineral ${ }^{1}$, \% & 1,35 & 0,43 & 0,90 & 0,34 \\
\hline Uréia, \% & 2,60 & 0,83 & 2,09 & 0,80 \\
\hline Sulfato de amônio, \% & 0,42 & 0,13 & 0,40 & 0,15 \\
\hline Sal, \% & 1,50 & 0,48 & 1,24 & 0,47 \\
\hline
\end{tabular}

Tabela 2 - Composição química dos ingredientes utilizados na ração experimental

\begin{tabular}{lrrr}
\hline Item & $\begin{array}{c}\text { Silagem } \\
\text { de milho }\end{array}$ & $\begin{array}{r}\text { Farelo } \\
\text { de soja }\end{array}$ & $\begin{array}{r}\text { Milho } \\
\text { moído }\end{array}$ \\
\hline Matéria seca (\%) & 26,53 & 88,65 & 85,14 \\
Matéria orgânica (\%MS) & 92,25 & 94,03 & 98,94 \\
Proteína bruta (\%MS) & 5,75 & 49,14 & 8,17 \\
NIDN/N (\% PB) & 20,76 & 6,10 & 21,25 \\
Extrato etéreo (\%MS) & 2,51 & 1,25 & 2,56 \\
FDNcp (\%MS) & 52,62 & 15,84 & 16,33 \\
Fibra em detergente & 56,43 & 18,93 & 18,44 \\
neutro (\%MS) & & & \\
CNFcp (\%MS) & 31,37 & 27,80 & 71,88 \\
Carboidratos não-fibrosos (\%MS) & 27,56 & 24,71 & 69,77 \\
Fibra em detergente ácido (\%MS) & 34,18 & 11,52 & 2,57 \\
Lignina (\%MS) & 4,18 & 0,50 & 0,58 \\
Sílica (\%MS) & 2,77 & 0,00 & 0,17 \\
FDNi (\%MS) & 23,26 & 2,41 & 1,70 \\
Fibra em detergente & 13,46 & 0,86 & 0,72 \\
ácido indigestível (\%MS) & & & \\
\hline
\end{tabular}


Tabela 3 - Composição química dos concentrados e das dietas experimentais

\begin{tabular}{|c|c|c|c|c|}
\hline \multirow[t]{2}{*}{ Item } & \multicolumn{2}{|c|}{$1,00 \%$ do $\mathrm{PV}$} & \multicolumn{2}{|c|}{$1,25 \%$ do $\mathrm{PV}$} \\
\hline & Concentrado & Dieta & Concentrado & Dieta \\
\hline Matéria seca, \% & 85,78 & 48,34 & 86,01 & 51,91 \\
\hline Matéria orgânica, \% & 94,27 & 93,76 & 95,25 & 94,18 \\
\hline Proteína bruta, \% & 22,71 & 11,40 & 18,03 & 10,68 \\
\hline Extrato etéreo, \% & 2,14 & 2,91 & 2,27 & 2,89 \\
\hline FDNcp, \% & 15,12 & 42,54 & 15,34 & 40,03 \\
\hline $\begin{array}{l}\text { Carboidratos } \\
\text { não-fibrosos, \% }\end{array}$ & 59,02 & 38,37 & 63,38 & 42,06 \\
\hline $\begin{array}{l}\text { Fibra em detergente } \\
\text { neutro indigestível, \% }\end{array}$ & 2,11 & 14,96 & 1,77 & 13,61 \\
\hline $\begin{array}{l}\text { Fibra em detergente } \\
\text { ácido indigestível, \% }\end{array}$ & 1,32 & 8,61 & 0,86 & 7,74 \\
\hline $\begin{array}{l}\text { Nutrientes digestíveis } \\
\text { totais, \% }\end{array}$ & - & 72,15 & - & 72,28 \\
\hline
\end{tabular}

A quantidade de ração oferecida e de sobras, por animal, foi registrada diariamente. Foram coletadas ainda amostras diárias do volumoso e das sobras e, ao final de cada semana, uma amostra composta foi elaborada e préseca. Posteriormente, foi feita outra amostra composta, proporcional por período de 28 dias, com base no peso seco ao ar de cada amostra semanal. Os alimentos concentrados foram amostrados diretamente na fábrica de rações da Universidade Federal de Viçosa, durante a mistura, e, ao final do experimento, formaram uma amostra composta (farelo de soja e milho moído).

Todas as pré-secagens foram realizadas em estufa ventilada $\left(65^{\circ} \mathrm{C}\right)$ e as moagens, em moinho de peneira de malha de $1 \mathrm{~mm}$. As amostras obtidas foram armazenadas em recipientes de plástico para posteriores análises laboratoriais.

O experimento teve duração de 112 dias, divididos em quatro períodos de 28 dias, ao final dos quais os animais eram pesados. Todas as pesagens foram precedidas de jejum alimentar de sólidos de 16 horas. As pesagens ao final de cada período tinham como objetivo monitorar o ganho de peso dos animais e proporcionar ajuste semanal na quantidade de concentrado fornecido. Com base do ganho médio obtido por animal no período anterior, o peso vivo foi estimado, ao início de cada semana, e a oferta do concentrado foi corrigida semanalmente com base nesse peso estimado.

$\mathrm{O}$ abate ao final do experimento foi realizado de forma escalonada e aleatória, sempre com um animal de cada um dos seis tratamentos por dia, totalizando três dias de abate. Dessa forma, os animais permaneceram 106, 110 ou 112 dias em confinamento.

Após o abate, o trato gastrintestinal (rúmen, retículo, omaso, abomaso e intestinos delgado e grosso) de cada animal foi esvaziado e lavado. Os pesos de coração, pulmões, fígado, baço, rins, gordura interna, carne industrial, mesentério, cauda e aparas (traquéia, esôfago e aparelho reprodutor), juntamente com os do trato gastrintestinal lavado, foram somados aos das demais partes do corpo (carcaça, cabeça, couro, pés e sangue) para determinação do peso de corpo vazio (PCVZ). A relação média obtida entre o PCVZ e o peso vivo (PV) dos animais-referência foi utilizada para a estimar o PCVZ inicial dos animais mantidos no experimento.

O couro foi pesado e uma amostra de $400 \mathrm{~cm}^{2}$, retirada da região posterior esquerda de cada animal, foi picada e armazenada a $-20^{\circ} \mathrm{C}$ para posteriores análises laboratoriais. Dentro de cada nível de concentrado, foi sorteado um animal, aleatoriamente, para retenção da cabeça e de dois membros (um anterior e outro posterior). A cabeça e os membros foram dissecados em couro, tecido mole e osso. O peso do couro obtido na dissecação da cabeça e dos membros foi adicionado ao couro retirado no momento do abate, obtendo-se, assim, o peso total do couro de cada animal. O tecido mole da cabeça e dos pés foi moído, enquanto os ossos foram serrados, amostrados e armazenados para posteriores análises laboratoriais. As composições física e química da cabeça e dos membros obtidas nos animais sorteados, dentro de cada nível de concentrado, foram utilizadas para a obtenção das composições dos demais animais do mesmo nível de concentrado.

A carcaça de todos os animais foi dividida e as meiascarcaças foram pesadas e resfriadas em câmara fria a $-5^{\circ} \mathrm{C}$ durante aproximadamente 18 horas. Decorrido esse tempo, as meias-carcaças foram retiradas da câmara fria, pesadas e uma amostra da carcaça esquerda, correspondente à seção entre a $9^{\mathrm{a}}$ e $11^{\mathrm{a}}$ costelas (seção HH), foi obtida para dissecação e predição das proporções de músculos, ossos e tecido adiposo na carcaça, segundo equações preconizadas por Hankins \& Howe (1946):

Proporção de músculo: $\mathrm{Y}=16,08+0,80 \mathrm{X}$;

Proporção de tecido adiposo: $\mathrm{Y}=3,54+0,80 \mathrm{X}$;

Proporção de ossos: $\mathrm{Y}=5,52+0,57 \mathrm{X}$, em que $\mathrm{X}$ é porcentagem dos componentes na seção HH.

Também foram testadas as equações propostas por Paulino (2002) para predição dos componentes minerais no peso de corpo vazio:

$\%$ Ca PCVZ = 0,410731 + 0,632149 X;

$\% \mathrm{P} P C V Z=0,321949+0,446450 \mathrm{X}$;

$\% \mathrm{Na} P C V Z=0,069185+0,750630 \mathrm{X}$;

$\% \mathrm{KPCVZ}=0,0240694+0,758359 \mathrm{X}$;

$\%$ Mg PCVZ = 0,0156984 + 0,436160 X;

em que $X$ refere-se aos teores desses componentes na seção HH. 
Os dados estimados pela seção entre a 9a e 11a costelas e observados na carcaça e no peso de corpo vazio foram comparados por meio de análise de regressão, de modo que $\mathrm{H}_{\mathrm{o}}: \beta_{0}=0$ e $\beta_{1}=1$ e $\mathrm{H}_{\mathrm{a}}$ : não $\mathrm{H}_{\mathrm{o}}$. Para o valor $\mathrm{P}$ menor de 0,05 detectou-se diferença entre valores observados e estimados.

A meia-carcaça direita de cada animal foi totalmente dissecada, os componentes músculo, gordura e ossos foram separados e, posteriormente, pesados para avaliação da composição física da carcaça. Os tecidos muscular e adiposo foram moídos, ao passo que o tecido ósseo foi serrado. Uma amostra representativa de cada componente foi retirada e, posteriormente, foi obtida uma amostra composta de carne + gordura, proporcional ao peso dos componentes na carcaça. Para amostragem do tecido ósseo, os ossos da carcaça foram divididos em três categorias: ossos longos, costelas e vértebras. Cada tipo de osso foi pesado separadamente, retirando-se, proporcionalmente, uma subamostra de cada categoria. Depois de homogeneizadas, as subamostras foram utilizadas na formação de uma amostra dos ossos da carcaça. Todos os procedimentos descritos acima foram realizados como descrito por Paulino (2002), de modo que os animais-referência passaram pelo mesmo processo.

O rúmen, retículo, omaso, abomaso, intestino delgado, intestino grosso, gordura interna, mesentério, fígado, coração, rins, pulmão, língua, baço, carne industrial e aparas (esôfago, traqueia e aparelho reprodutor) foram triturados conjuntamente em cutter industrial por 20 minutos, homogeneizados e, então, uma amostra denominada órgãos e vísceras foi obtida.

As amostras de sangue foram coletadas imediatamente após o abate e a sangria, acondicionadas em recipiente de vidro e levadas à estufa de ventilação forçada $\left(60^{\circ} \mathrm{C}\right)$ durante 48 a 72 horas, para quantificação do teor de MS. Em seguida, foram moídas em moinho de bola e acondicionadas em recipientes para posteriores análises de nitrogênio total, extrato etéreo e minerais, conforme relatado por Silva \& Queiroz (2002).

As amostras de órgãos e vísceras (200g), de músculo + gordura (200 g), de couro (100 g), de ossos (100 g) e tecidos mole da cabeça $(200 \mathrm{~g})$ e dos pés $(100 \mathrm{~g})$ foram acondicionadas em vidros com capacidade de $500 \mathrm{~mL}$ e levadas à estufa a $105^{\circ} \mathrm{C}$, por período entre 48 a 72 horas, para avaliação da matéria seca gordurosa (MSG). Posteriormente, foram submetidas a lavagens sucessivas com éter de petróleo, obtendo-se a matéria seca pré-desengordurada (MSPD). Em seguida, as amostras foram moídas em moinho de bola para posteriores avaliações de nitrogênio total, extrato etéreo e cinzas, conforme Silva \& Queiroz (2002). A gordura removida no pré-desengorduramento foi calculada pela diferença entre a MSG e a MSPD, cujo resultado foi adicionado aos obtidos para o extrato etéreo residual na MSPD, para determinação do teor total de gordura.

Os conteúdos corporais de gordura, proteína e macrominerais foram determinados em relação às suas concentrações nos órgãos e nas vísceras, no couro, no sangue, na cabeça, nos pés e nas amostras da meia-carcaça esquerda (ossos e músculo + gordura).

As estimativas da energia corporal foram obtidas a partir dos teores corporais de proteína e gordura e seus respectivos equivalentes calóricos, conforme a equação preconizada pelo ARC (1980):

$$
\mathrm{CE}=5,6405 \mathrm{X}+9,3929 \mathrm{Y} \text {, }
$$

em que CE é conteúdo energético (Mcal); X, proteína corporal (kg); Y, gordura corporal (kg).

Os resultados foram interpretados estatisticamente por meio de análises de variância e regressão, utilizando-se o programa Statistical Analysis System (SAS, 1997).

\section{Resultados e Discussão}

Nas análises estatísticas das regressões encontradas, a hipótese de nulidade para as três características foi rejeitada, ou seja, a seção HH não permitiu estimar bem os tecidos adiposo, muscular e ósseo na carcaça de bovinos Nelore (Tabelas 4 e 5). O tecido muscular foi subestimado em $8,83 \%$ pela seção HH e o tecido adiposo foi superestimado em 37,45\% (Figura 1). O tecido ósseo foi o que se comportou de maneira mais próxima, porém sem a confirmação estatística. Lanna (1988), Silva (2001) e Paulino et al. (2005) também observaram esse comportamento para o tecido adiposo, entretanto, a seção HH foi desenvolvida para animais taurinos.

Tabela 4 - Porcentagens dos tecidos muscular, adiposo e ósseo observadas e estimadas pela seção $\mathrm{HH}$

\begin{tabular}{lcc}
\hline Item & Composição observada & Composição estimada \\
\cline { 2 - 3 } & \multicolumn{2}{c}{ Tecido muscular } \\
Média (\%) & 34,45 & 58,76 \\
Desvio-padrão (\%) & 3,50 & 3,35 \\
Amplitude (\%) & $60,21-66,54$ & $51,59-64,04$ \\
& Tecido adiposo \\
Média (\%) & 24,81 \\
Desvio-padrão (\%) & 5,60 & 6,14 \\
Amplitude (\%) & $9,12-28,43$ & $17,10-28,16$ \\
& 18,05 & 16,96 \\
Média (\%) & 2,89 & 2,63 \\
Desvio-padrão (\%) & $12,70-23,21$ & $13,46-21,91$ \\
Amplitude (\%) & \multicolumn{2}{c}{ Tecido ósseo } \\
\hline
\end{tabular}


Tabela 5 - Valores observados e estimados para os tecidos muscular, adiposo e ósseo da carcaça

\begin{tabular}{lcccc}
\hline Tecido & $\begin{array}{c}\text { Intercepto } \\
\left(\beta_{0}\right)\end{array}$ & $\begin{array}{c}\text { Coeficiente de } \\
\text { inclinação }\left(\beta_{1}\right)\end{array}$ & Valor $\mathrm{P}^{1}$ & $\mathrm{r}^{2}$ \\
\hline Muscular & 20,93255 & 0,58688 & $<0,0001$ & 0,3748 \\
Adiposo & 7,06440 & 0,98277 & $<0,0001$ & 0,8035 \\
Ósseo & 2,64881 & 0,81797 & 0,0123 & 0,8036 \\
\hline${ }^{1} \mathrm{H}_{0}: \beta_{0}=0$ e $\beta_{1}=1, \mathrm{H}_{\mathrm{a}}=$ não $\mathrm{H}_{\mathrm{o}}$. & & &
\end{tabular}
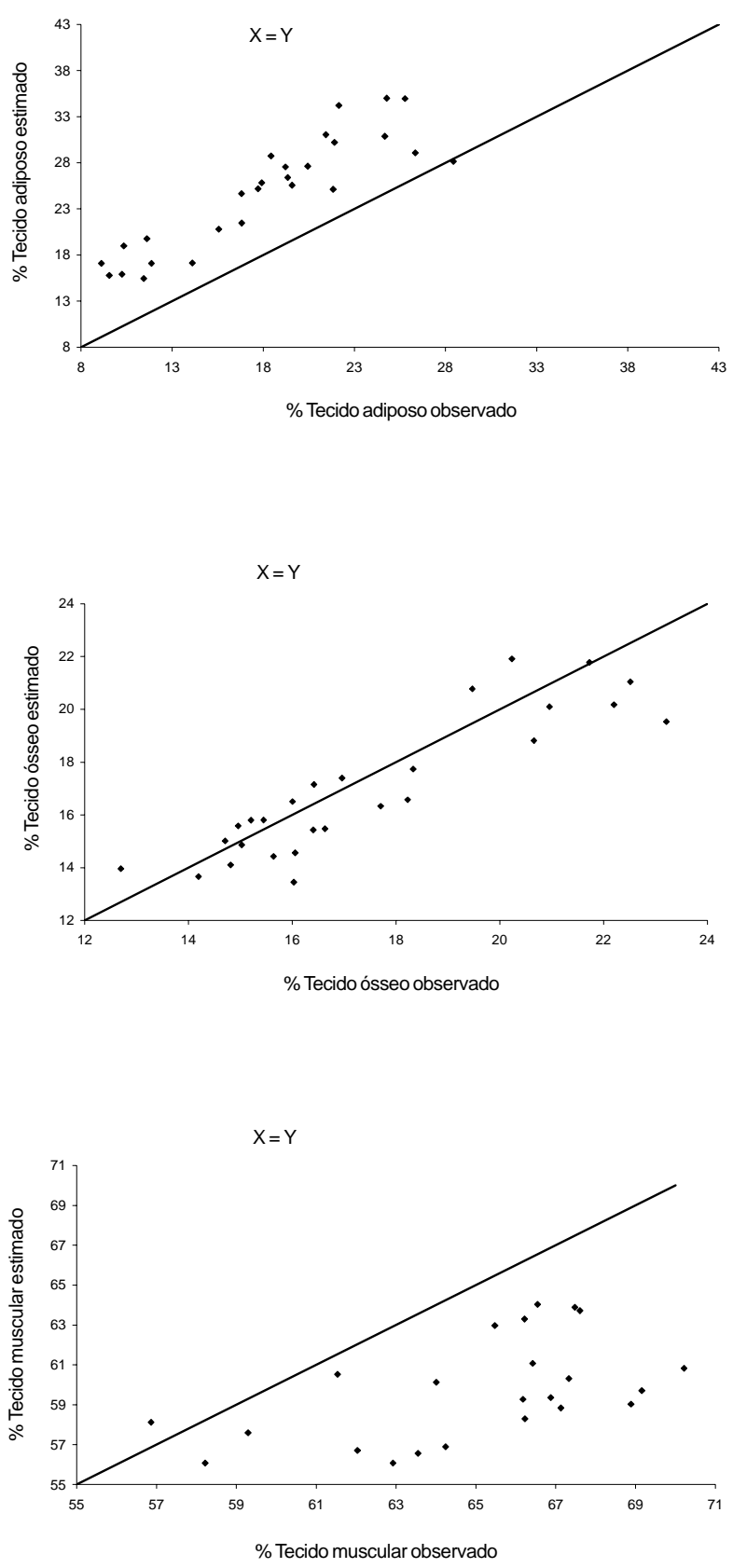

Figura 1 - Relação entre as porcentagens dos tecidos adiposo, ósseo e muscular observados na carcaça e estimadas pela seção HH.
Karnuah et al. (2001) afirmaram que a acurácia de uma equação de predição deve reduzir-se quando as equações são aplicadas para estimar a composição de carcaça de animais pertencentes a outra população ou a outro grupamento genético.

No entanto, a seção HH é uma alternativa promissora para o desenvolvimento de pesquisas, pois dispensa a dissecação completa da carcaça (Paulino, 2002) e prediz bem o teor desses três tecidos na carcaça de animais anelorados castrados. Para estimação da composição química do animal, são necessárias equações que estimem a composição química do animal a partir da composição química da seção HH. Algumas pesquisas no Brasil já foram realizadas com esse intuito e algumas equações já foram desenvolvidas (Lanna, 1988; Alleoni et al., 2001; Silva, 2001; Henrique et al., 2003; Paulino et al., 2005).

Valadares Filho et al. (2006) compilaram dados brasileiros, incluindo os deste trabalho, e elaboraram equações para predição dos teores de água, extrato etéreo, proteína e minerais no peso de corpo vazio de animais zebuínos, no entanto, são necessários mais trabalhos para a validação dessas equações.

A literatura brasileira já dispõe de grande quantidade de dados para a predição da composição química de proteína e energia no corpo vazio a partir da seção HH. Entretanto, apenas Paulino (2002) apresentou equações para a predição dos teores de macrominerais no peso de corpo vazio a partir de suas composições na seção HH.

Apenas a equação para o conteúdo de cálcio foi eficiente em estimar a porcentagem desse mineral no corpo vazio dos animais (Tabela 6; Figura 2). As equações para magnésio e fósforo subestimaram, em média, em 14,22 e $7,72 \%$ os teores desses minerais no corpo vazio e aquelas para potássio e sódio superestimaram, em média, em 7,41 e 10,31\% os teores desses minerais no corpo vazio.

As equações utilizadas para estimação do teor de minerais no peso de corpo vazio dos animais foram obtidas com dados de apenas 19 animais presentes no experimento de Paulino (2002) e, para obtenção de equações confiáveis, são necessários mais dados, para que se tenha a maior representabilidade possível. Essa pode ser uma explicação para que apenas a equação para o cálcio (Tabela 7) tenha sido eficiente em estimar a composição no corpo vazio dos animais. Além disso, os animais utilizados por Paulino (2002) eram apenas anelorados e isso pode diminuir a aplicabilidade das equações propostas para animais Nelore puros (Karnuah et al., 2001).

A partir dos dados obtidos neste experimento e somados aos obtidos por Paulino (2002), foram desenvolvidas novas equações para estimar os teores de fósforo, magnésio, 
Tabela 6 - Porcentagens dos macrominerais observadas ou estimadas pela seção HH

\begin{tabular}{|c|c|c|}
\hline \multirow[t]{2}{*}{ Item } & Composição observada & Composição estimada \\
\hline & \multicolumn{2}{|c|}{ Cálcio } \\
\hline Média (\%) & 2,42 & 2,46 \\
\hline Desvio-padrão (\%) & 0,51 & 0,51 \\
\hline \multirow[t]{2}{*}{ Amplitude (\%) } & $1,70-3,60$ & $1,61-3,80$ \\
\hline & \multicolumn{2}{|c|}{ Fósforo } \\
\hline Média (\%) & 0,86 & 0,79 \\
\hline Desvio-padrão (\%) & 0,15 & 0,12 \\
\hline \multirow[t]{2}{*}{ Amplitude (\%) } & $0,634-1,235$ & $0,619-1,062$ \\
\hline & \multicolumn{2}{|c|}{ Sódio } \\
\hline Média (\%) & 0,149 & 0,165 \\
\hline Desvio-padrão (\%) & 0,008 & 0,016 \\
\hline \multirow[t]{2}{*}{ Amplitude (\%) } & $0,133-0,170$ & $0,141-0,193$ \\
\hline & \multicolumn{2}{|c|}{ Magnésio } \\
\hline Média (\%) & 0,049 & 0,042 \\
\hline Desvio-padrão (\%) & 0,009 & 0,006 \\
\hline \multirow[t]{2}{*}{ Amplitude (\%) } & $0,035-0,076$ & $0,032-0,055$ \\
\hline & \multicolumn{2}{|c|}{ K } \\
\hline Média (\%) & 0,182 & 0,197 \\
\hline Desvio-padrão (\%) & 0,014 & 0,012 \\
\hline Amplitude (\%) & $0,158-0,211$ & $0,175-0,223$ \\
\hline
\end{tabular}
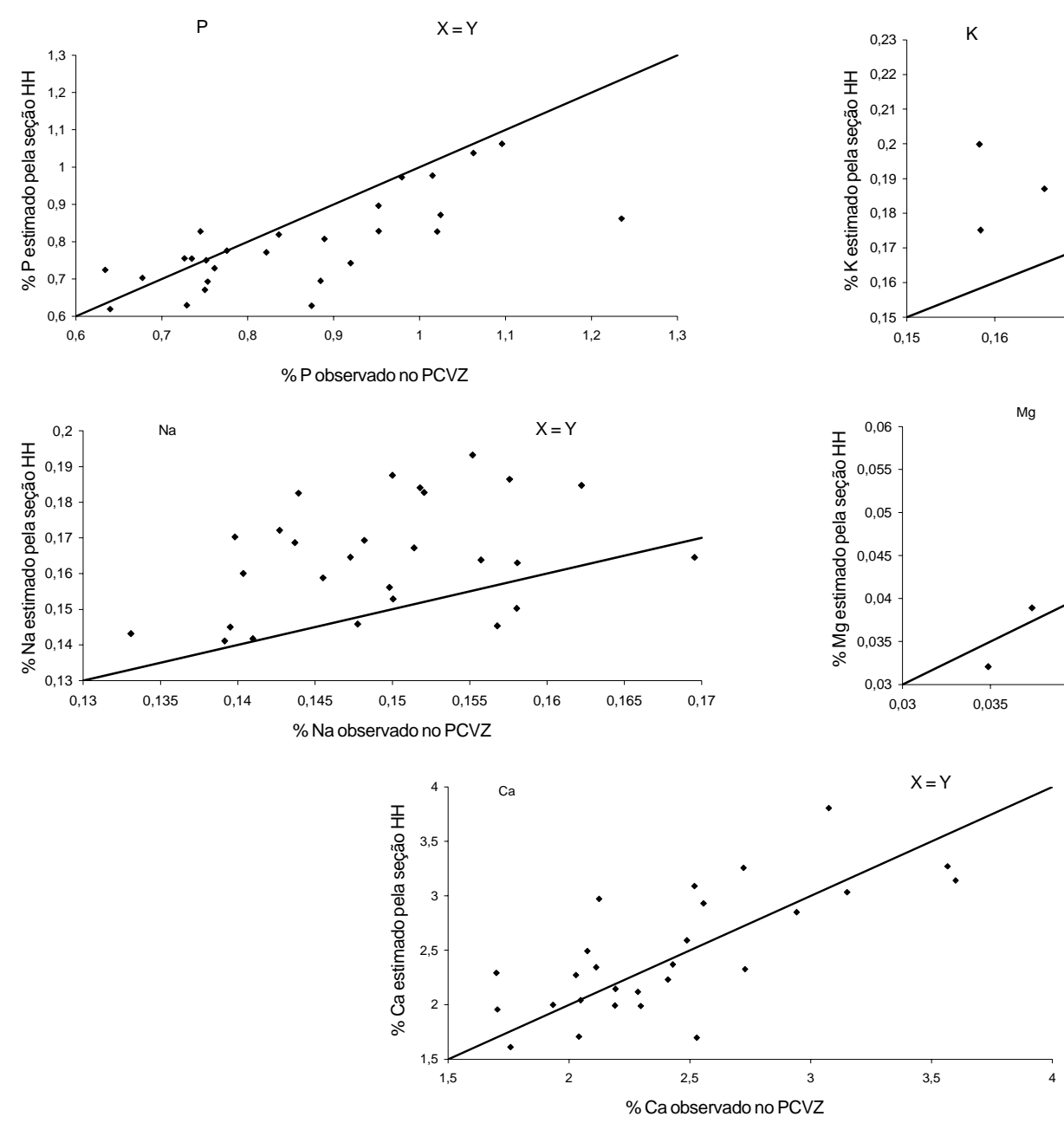

Figura 2 - Relação entre os teores (\%) de macrominerais observados no corpo vazio e estimados pela seção HH. vazio

${ }^{1} \mathrm{H}_{0}: \beta_{0}=0$ e $\beta_{1}=1, \mathrm{H}_{\mathrm{a}}=$ não $\mathrm{H}_{\mathrm{o}}$. (Figura 3). $(\mathrm{P}<0,0001)$; $(\mathrm{P}<0,0001)$;

Tabela 7 - Regressões entre valores observados e estimados das porcentagens dos macrominerais no peso de corpo

\begin{tabular}{lcccc}
\hline Tecido & $\begin{array}{c}\text { Intercepto } \\
\left(\beta_{0}\right)\end{array}$ & $\begin{array}{c}\text { Coeficiente de } \\
\text { inclinação }\left(\beta_{1}\right)\end{array}$ & Valor $\mathrm{P}^{1}$ & $\mathrm{r}^{2}$ \\
\hline Cálcio & 0,52391 & 0,80304 & 0,3667 & 0,5286 \\
Fósforo & 0,29725 & 0,57686 & $<0,0001$ & 0,5437 \\
Sódio & 0,05993 & 0,70134 & $<0,0001$ & 0,1346 \\
Magnésio & 0,01953 & 0,46488 & $<0,0001$ & 0,5494 \\
Potássio & 0,14220 & 0,29706 & $<0,0001$ & 0,1149 \\
\hline
\end{tabular}

sódio e potássio no corpo vazio de animais zebuínos a partir da composição desses minerais na seção HH. Apesar da não-significância observada para o cálcio, em virtude do baixo número de repetições que gerou sua equação, também foram desenvolvidas novas equações para este mineral

\% P PCVZ = 0,38222 + 0,42405 * \% P seção HH, $\mathrm{r}^{2}=0,70$

\% Na PCVZ = 0,11108 + 0,28862 * \% Na seção HH, $\mathrm{r}^{2}=0,31$
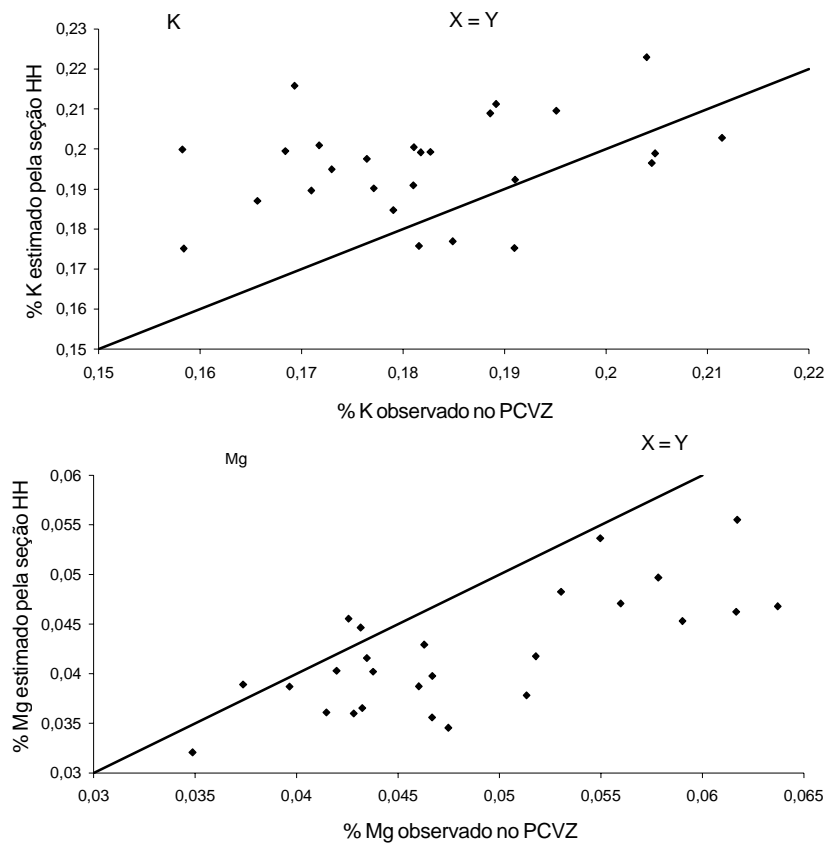

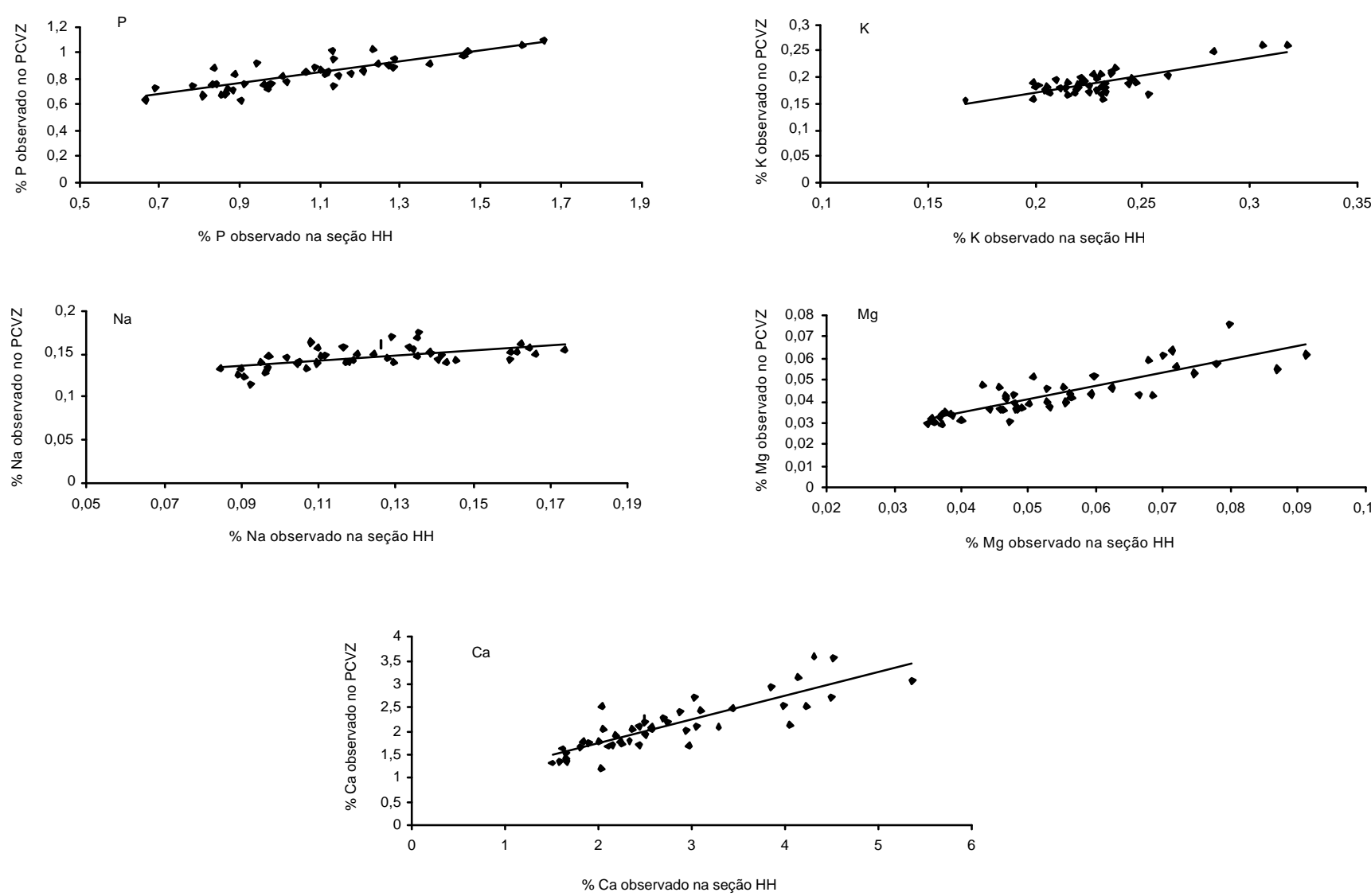

Figura 3 - Representação dos valores de macrominerais observados na seção HH e no peso de corpo vazio (PCVZ).

$\% \mathrm{~K} \mathrm{PCVZ}=0,03565+0,67317 * \% \mathrm{~K}$ seção $\mathrm{HH}, \mathrm{r}^{2}=0,60$ $(\mathrm{P}<0,0001)$;

$\% \mathrm{Mg} P C V Z=0,00963+0,62601 * \% \mathrm{Mg}$ seção HH, $\mathrm{r}^{2}=0,73$ $(\mathrm{P}<0,0001)$;

\% Ca PCVZ $=0,7334+0,5029 * \%$ Ca seção HH, $\mathrm{r}^{2}=0,71$ $(\mathrm{P}<0,0001)$.

\section{Conclusões}

As equações propostas por Hankins \& Howe (1946) não são eficientes para estimar a composição física da carcaça de bovinos Nelore. A equação proposta por Paulino (2002) é eficiente para estimar a concentração de cálcio no corpo vazio a partir da concentração desse mineral na seção HH. Propõe-se o uso de novas equações para estimar o conteúdo corporal dos macrominerais estudados a partir de sua concentração na seção HH.

\section{Literatura Citada}

AGRICULTURAL RESEARCH COUNCIL - ARC. The nutrient requirements of ruminants livestock. London: 1980. 351p.
ALLEONI, G.F.; LEME, P.R.; BOIN, C. et al. Determinação da composição do corpo vazio, do ganho de peso e das exigências de energia e proteína para mantençae ganho de peso em bovinos da raça Nelore, Canchim e Brangus. Nova Odessa: Instituto de Zootecnia de Nova Odessa, 2001. (Relatório Científico Fapesp: Processo 97/02590-5).

HANKINS, O.G.; HOWE, P.E. Estimation of the composition of beef carcasses and cuts. [T.B.]: United States Department of Agriculture, 1946. p.1-19. (Technical Bulletin, 926).

HENRIQUE, W.; SAMPAIO, A.A.M.; LEME, P.R. et al. Estimativa da composição química corporal de tourinhos Santa Gertrudis a partir da composição química e física das $9-10-11^{a}$ costelas. Revista Brasileira de Zootecnia, v.32, n.3, p.709-718, 2003.

KARNUAH, A.B.; MORIYA, K.; NAKANISHI, N. et al. Computer image analysis for prediction of carcass composition from crosssection of Japanese Black steers. Journal of Animal Science, v.79, p.2851-2856. 2001.

LANNA, D.P.D. Estimativa da composição química do corpo vazio de tourinhos Nelore através da gravidade específica da carcaça e da composição de corte das costelas. 1988. 131f. Dissertação (Mestrado em Nutrição Animal) - Escola Superior de Agricultura "Luiz de Queiroz"/Universidade de São Paulo, Piracicaba, 1988.

NATIONAL RESEARCH COUNCIL - NRC. Nutrients requirements of beef cattle. 7.ed. National Academic Press. Washington, D.C.: 1996. 242p.

PAULINO, P.V.R. Exigências nutricionais e validação da seção HH para predição da composição corporal de zebuínos. 2002. 158f. Dissertação (Mestrado em Zootecnia) - Universidade Federal de Viçosa, Viçosa, MG, 2002. 
PAULINO, P.V.R.; COSTA, M.A.L.; VALADARES FILHO, S.C. et al. Validação das equações desenvolvidas por hankins e howe para predição da composição da carcaça de zebuínos e desenvolvimento de equações para estimativa da composição corporal. Revista Brasileira de Zootecnia, v.34, n.1, p.327-339, 2005.

SILVA, D.J.; QUEIROZ, A.C. Análise de alimentos (métodos químicos e biológicos). 3.ed. Viçosa, MG: Editora UFV, 2002. $165 \mathrm{p}$.

SILVA, F.F. Desempenho, características de carcaça, composição corporal e exigências nutricionais (de energia, proteína, aminoácidos e macrominerais) de novilhos Nelore, nas fases de recria e engorda, recebendo diferentes níveis de concentrado e proteína. 2001. 211f. Tese (Doutorado em

Zootecnia) - Universidade Federal de Viçosa, Viçosa, MG, 2001.

STATISTICAL ANALYSIS SYSTEM - SAS. SAS/STAT software: changes and enhancements through release 6.12. Cary: SAS Institute, 1997. 1167p

VALADARES FILHO, S.C.; PAULINO, P.V.R.; MAGALHÃES, K.A Exigências nutricionais de zebuínos e tabelas brasileiras de composição de alimentos para bovinos. 1.ed. Viçosa, MG: Universidade Federal de Viçosa, Departamento de Zootecnia, 2006. $141 \mathrm{p}$. 